\title{
Clinical Profiles, Demographic Features, and Maternal Outcomes among Coronavirus Disease Positive Pregnant Women: A Cross-sectional Study
}

\author{
Zaheera Saadia $^{1 *}$, Robina Farruk ${ }^{2}$, Sumaira Kanwal ${ }^{3}$, Quratulain Shahzad ${ }^{3}$ \\ ${ }^{1}$ Department of Obstetrics and Gynecology, Qassim University, Almulida, Al-Qassim, Saudi Arabia; ${ }^{2}$ Department of Obstetrics \\ and Gynecology, Sir Ganga Ram Hospital, Lahore, Punjab, Pakistan; ${ }^{3}$ Department of Obstetrics and Gynecology, Sir Ganga \\ Ram Hospital, Lahore, Punjab, Pakistan
}

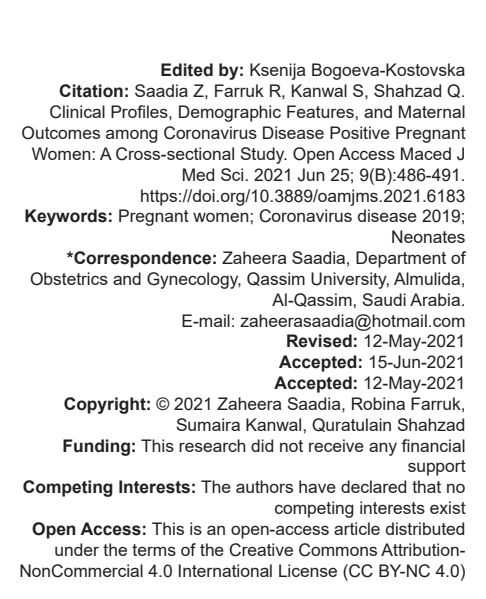

\begin{abstract}
BACKGROUND: Pregnant women are susceptible to coronavirus infection due to physiological changes in the circulatory and immunological parameters.

AIM: The current study aimed to determine the demographic factors, clinical symptoms, and fetal-maternal outcomes and also compare the blood parameters and chest X-ray results among coronavirus disease 2019 (COVID-19) positive and negative pregnant women.

MATERIALS AND METHODS: Complete blood count and Chest X-rays were performed as a routine in all pregnant women. Polymerase chain reaction for COVID-19 was performed for all women and the newborn.

RESULTS: The blood parameters revealed that a significantly greater proportion of COVID-19 positive pregnant women had abnormal hemoglobin, total leukocyte count, neutrophil count, lymphocyte count, monocyte count, bilirubin, aspartate aminotransferase, alanine aminotransferase, and urea.

CONCLUSIONS: The present study provided crucial insights into epidemiological and clinical features during the perinatal period. Chest X-rays and blood routine examination are reliable findings to prevent COVID-19 complications
\end{abstract} among pregnant women.

\section{Introduction}

In December 2019, a novel coronavirus was identified in China, causing multiple pneumonia cases. Globally, there was rapid spread, and the number of cases has increased. The World Health Organization designated the disease as coronavirus disease 2019 (COVID-19) in February 2020 [1]. Among the vulnerable group of the population, pregnant women are susceptible to coronavirus infection due to physiological alterations in the circulatory and immunological parameters [2].

During pregnancy, physiological changes occur, such as a decrease in the residual functional capacity of the lung, the height of the diaphragm, and changes in cellular immunity that lead to increased susceptibility to viral infections and more severe consequences in pregnant women [3]. Recently, severe sickness among pregnant women in the antenatal period has been reported in the previous studies. A study by Ellington et al. reported that approximately one-third of pregnant women were hospitalized compared with (5.8\%) non-pregnant women [4]. Similarly, Badr et al. reported a higher risk of complications and decompensation in the later trimesters of the pregnancy [5]. Yu et al. found that women who were receiving obstetrical care were asymptomatic; however, they developed symptoms within 2-3 days of their postpartum. The majority of the infections in their study were mild [6]. Apart from postpartum transmission (horizontal), multiple routes of transmission, including transplacental and immediate peripartum period through fetoplacental bleed, amniotic fluid, and breast milk, have been postulated. However, there is a lack of evidence for vertical transmission in pregnancy [7].

According to the Centers for Disease Control and Prevention (CDC), there is a paucity of information about the effects of Coronavirus on pregnancy and neonatal outcomes [8]. Therefore, during the COVID-19 pandemic, it is essential to acquire knowledge of pregnancy outcomes, including the severity of symptoms, potential complications during pregnancy, and the neonate's health conditions born to an infected mother, and the possibility of vertical 
transmission. However, there is limited comprehensive data regarding its side effects on pregnancy. The disease remains significantly heterogeneous both in its demographic characteristics and clinical features. Hence, the current study aimed (1) to determine the demographic factors, clinical symptoms, fetal-maternal outcomes among pregnant women; and (2) to compare the blood parameters and chest $X$-ray results among COVID-19 positive and negative pregnant women.

\section{Materials and Methods}

An observational study was conducted at Sir Ganga Ram Hospital, Lahore, Pakistan The hospital was the tertiary referral care center for COVID-19 cases in that region. A total of 94 pregnant women suspected of COVID-19 from April 2020 to May 2020 were referred to this center for medical facilities. The patients presented within 2-3 days of their onset of symptoms.

Patients' information was extracted from records and included age, address, gestational age, comorbidities, signs, and symptoms at onset, and information about neonates including birth weight, appearance, pulse, grimace, activity, and respiration (APGAR) score, neonatal intensive care unit (NICU) admissions, perinatal complication, and outcomes of pregnancy. The data were entered into an Excel Sheet directly. Only the electronic pro forma was used, and no paperwork was involved. The device used for data collection (iPad-device) was kept inside the data collecting zone (ward) and not removed from the ward at any time, and data were transferred through the internet to the department's main computer for analysis.

\section{Testing policy}

It was a hospital policy to perform complete blood count, blood sugar level, and comprehensive examination of urine as a routine in all pregnant women. Normal values for blood parameters are included in Table 1.

All those above, the normal range is considered abnormal. Polymerase chain reaction (PCR) for COVID-19 for all women and the newborn was performed.

Table 1: Normal hematology parameters in pregnancy

\begin{tabular}{llll}
\hline Hematology parameters & $1^{\text {st }}$ trimester & $2^{\text {nd }}$ trimester & $3^{\text {rd }}$ trimester \\
\hline Hemoglobin $(\mathrm{g} / \mathrm{dL})$ & $11.6-13.9$ & $9.7-14.8$ & $9.5-15.0$ \\
Total leukocyte $\left.{ }^{*} 103 / \mathrm{mm} 3\right)$ & $5.7-13.6$ & $5.6-14.8$ & $5.9-16.9$ \\
Neutrophil count $\left({ }^{*} 103 / \mathrm{mm} 3\right)$ & $3.6-10.1$ & $3.8-12.3$ & $3.9-13.1$ \\
Lymphocyte count $\left({ }^{*} 103 / \mathrm{mm} 3\right)$ & $1.1-3.6$ & $0.9-3.9$ & $1.0-3.6$ \\
Monocyte count $\left.{ }^{*} 103 / \mathrm{mm} 3\right)$ & $0.1-1.1$ & $0.1-1.1$ & $0.1-1.4$ \\
Platelet count $\left.{ }^{*} 109 / \mathrm{L}\right)$ & $174-391$ & $155-409$ & $146-429$ \\
Bilirubin $(\mathrm{mg} / \mathrm{dL})$ & $0.1-0.4$ & $0.1-0.8$ & $0.1-1.1$ \\
AST $(\mathrm{U} / \mathrm{L})$ & $3-23$ & $3-33$ & $4-32$ \\
ALT $(\mathrm{U} / \mathrm{L})$ & $3-30$ & $2-33$ & $2-25$ \\
Urea $(\mathrm{mg} / \mathrm{dL})$ & $7-12$ & $3-13$ & $3-11$ \\
Creatinine $(\mathrm{mg} / \mathrm{dL})$ & $0.4-0.7$ & $0.4-0.8$ & $0.4-0.9$ \\
\hline AST: Aspartate Aminotransferase, ALT: Alanine Aminotransferase.
\end{tabular}

Open Access Maced J Med Sci. 2021 Jun 25; 9(B):486-491.
The qualitative COVID-19 PCR test was performed on VERSANT K PCR (SIEMENS) fully automated PCR System Extraction Siemens-Amplification Logix Smart (FDA Approved) using nasopharyngeal swabs. This test directly detects the viral RNA.

Due to the highly infectious nature of the disease, all precautions were ensured to keep the safety of data collectors in accordance with guidelines provided by the government of Pakistan [9]. According to the recommendations, all the health-care staff followed the doffing and donning sequence of total personal protective equipment, which included double layer gloves, goggles, head caps, N95 masks, and shoe covers. When aerosol-generating procedures were performed, face shields were used.

\section{Ethics}

The study was approved by the Institutional Review Board of the hospital. Informed consent was obtained from each pregnant woman. For the newborn infants, proxy written informed consent was obtained from the parent or legal guardian. Confidentiality of the data was maintained by keeping data anonymous in line with Helsinki's declaration.

\section{Statistical analysis}

The recorded data were compiled and entered into a spreadsheet computer program (Microsoft Excel 2010) and then exported to the data editor page of IBM SPSS version 22.0 (SPSS Inc., Chicago, Illinois, USA). Bivariate analysis was performed using the Chi-square test for the association of COVID-19 status of pregnant women with independent variables. For all tests, confidence interval and p-value were set at $95 \%$ and $\leq 0.05$, respectively.

\section{Results}

Table 2 shows the comparative evaluation of COVID-19 status in pregnant women according to demographic variables.

There was no significant association of age group (years) $(p=0.713)$, education $(p=0.11)$, and parity ( $p=0.891)$ with COVID-19 status. When compared according to the occupation, the majority of COVID-19 positive patients were housewives (97.9\%) followed by doctors $(2.1 \%)$, and the association was statistically significant ( $p=0.002)$ (Table 2).

Table 3 shows the fetomaternal outcome among COVID-19 and non-COVID-19 pregnant women.

There was no significant association of maternal death $(p=0.162)$, maternal complications 
Table 2: Comparative evaluation of COVID-19 in pregnant women according to demographic variables

\begin{tabular}{|c|c|c|c|c|}
\hline Demographic variables & $\begin{array}{l}\text { COVID-19 } \\
\text { positive } \mathrm{n}(\%)\end{array}$ & $\begin{array}{l}\text { COVID-19 } \\
\text { negative } \mathrm{n}(\%)\end{array}$ & $\mathrm{p}$-value & $\begin{array}{l}\text { Total } \mathrm{n} \\
(\%)\end{array}$ \\
\hline \multicolumn{5}{|l|}{ Age group (years) } \\
\hline$<30$ & $32(66.7)$ & $29(63)$ & \multirow[t]{2}{*}{0.713} & $61(64.9)$ \\
\hline More than 30 & $16(33.3)$ & $17(37)$ & & $33(35.1)$ \\
\hline \multicolumn{5}{|l|}{ Education } \\
\hline Uneducated & $13(27.1)$ & $5(10.9)$ & \multirow[t]{5}{*}{0.11} & 18 (19.1) \\
\hline Primary School & $6(12.5)$ & $6(13)$ & & $12(12.8)$ \\
\hline Secondary School & $15(31.2)$ & $13(28.3)$ & & $28(29.8)$ \\
\hline College Level & $13(27.1)$ & $16(34.8)$ & & 29 (30.9) \\
\hline University Level & $1(2.1)$ & $6(13)$ & & $7(7.4)$ \\
\hline \multicolumn{5}{|l|}{ Occupation } \\
\hline Housewife & 47 (97.9) & $30(65.2)$ & \multirow[t]{5}{*}{$0.002^{*}$} & 77 (81.9) \\
\hline Schoolteacher & 0 & $5(10.9)$ & & $5(5.3)$ \\
\hline Nurse & 0 & $1(2.2)$ & & $1(1.1)$ \\
\hline Doctor & $1(2.1)$ & $6(13)$ & & $7(7.4)$ \\
\hline Housemaid & 0 & $4(8.7)$ & & $4(4.3)$ \\
\hline \multicolumn{5}{|l|}{ Source of infection } \\
\hline Family & $10(21.3)$ & - & \multirow[t]{3}{*}{-} & $10(21.3)$ \\
\hline Workplace & 0 & - & & 0 \\
\hline Not known & $37(78.7)$ & - & & $37(78.7)$ \\
\hline \multicolumn{5}{|l|}{ Parity } \\
\hline$\leq 2$ & $37(77.1)$ & $36(78.3)$ & \multirow[t]{3}{*}{0.891} & $73(77.7)$ \\
\hline More than 2 & $11(22.9)$ & $10(21.7)$ & & $21(22.3)$ \\
\hline Total & 48 (51.1) & 46 (48.9) & & $94(100)$ \\
\hline
\end{tabular}

disease 2019.

$(p=0.513)$, baby's weight $(p=0.249)$, APGAR score $(p=0.161)$, and NICU admission $(p=0.24)$ with COVID-19 status. However, the mode of delivery was significantly ( $p=0.001)$ associated with COVID-19 status. The majority of COVID-19 positive subjects $(80 \%)$ had lower segment caesarean section delivery, while the majority of COVID-19 negative subjects (63\%) had an spontaneous vaginal delivery type of delivery (Table 3).

Table 3: Comparative evaluation of fetomaternal outcome among COVID-19 and non-COVID-19 pregnant women

\begin{tabular}{|c|c|c|c|c|}
\hline Independent variables & $\begin{array}{l}\text { COVID-19 } \\
\text { positive n (\%) }\end{array}$ & $\begin{array}{l}\text { COVID-19 } \\
\text { negative n (\%) }\end{array}$ & $\mathrm{p}$-value & $\begin{array}{l}\text { Total n } \\
(\%)\end{array}$ \\
\hline \multicolumn{5}{|l|}{ Maternal death } \\
\hline No & $46(95.8)$ & $46(100)$ & \multirow{2}{*}{0.162} & $92(97.9$ \\
\hline Yes & $2(4.2)$ & 0 & & $2(2.1)$ \\
\hline \multicolumn{5}{|l|}{ ICU admission } \\
\hline Yes & $7(14.9)$ & 0 & \multirow[t]{2}{*}{-} & $7(14.9)$ \\
\hline No & $40(85.1)$ & 0 & & $40(85.1)$ \\
\hline \multicolumn{5}{|l|}{ Maternal Complications } \\
\hline Renal failure & 0 & 0 & \multirow[t]{8}{*}{0.513} & 0 \\
\hline Cardiac failure & 0 & 0 & & 0 \\
\hline HEELP syndrome & 0 & 0 & & 0 \\
\hline Preeclampsia & 0 & 0 & & 0 \\
\hline Preterm labor & $1(2.1)$ & 0 & & $1(1.1)$ \\
\hline PPROM & $1(2.1)$ & 2 & & $3(3.2)$ \\
\hline Cord Prolapse & 0 & 0 & & 0 \\
\hline No complication & $46(95.8)$ & $44(95.7)$ & & $90(95.7)$ \\
\hline \multicolumn{5}{|l|}{ Mode of delivery } \\
\hline SVD & $5(20)$ & $29(63)$ & \multirow[t]{2}{*}{$0.001^{*}$} & $34(47.9)$ \\
\hline LSCS & $20(80)$ & $17(37)$ & & $37(52.1)$ \\
\hline \multicolumn{5}{|l|}{ Baby's weight } \\
\hline$<2.5$ & $7(28)$ & $7(16.3)$ & \multirow[t]{2}{*}{0.249} & $14(20.6$ \\
\hline More than 2.5 & $18(72)$ & $36(83.7)$ & & $54(79.4)$ \\
\hline \multicolumn{5}{|l|}{ APGAR score } \\
\hline Below 6 & $2(8)$ & $1(2.2)$ & \multirow[t]{3}{*}{0.161} & $3(4.3)$ \\
\hline $6-9$ & $6(24)$ & $5(11.1)$ & & $11(15.7)$ \\
\hline Ten and above & $17(68)$ & $39(86.7)$ & & $56(80)$ \\
\hline \multicolumn{5}{|l|}{ NICU admission } \\
\hline Yes & $3(12)$ & $2(4.4)$ & \multirow[t]{2}{*}{0.24} & $5(7.1)$ \\
\hline No & $22(88)$ & $43(95.6)$ & & $65(92.9$ \\
\hline \multicolumn{5}{|l|}{ Fetal PCR } \\
\hline Positive & - & - & \multirow[t]{2}{*}{-} & - \\
\hline Negative & $24(100)$ & - & & $24(100)$ \\
\hline
\end{tabular}

When blood parameters were compared among COVID positive and COVID negative subjects, significant differences were observed in hemoglobin, total leukocyte count (TLC), neutrophil count, lymphocyte count, monocyte count, bilirubin, aspartate aminotransferase (AST), alanine aminotransferase (ALT), and urea levels among the COVID-19 positive group than COVID-19 negative group (Table 4).

Table 4: Comparative assessment of blood parameters among COVID-19 and non-COVID-19 pregnant women

\begin{tabular}{|c|c|c|c|c|}
\hline Independent variables & $\begin{array}{l}\text { COVID-19 } \\
\text { positive } \mathrm{n}(\%)\end{array}$ & $\begin{array}{l}\text { COVID-19 } \\
\text { negative } \mathrm{n}(\%)\end{array}$ & $p$-value & $\begin{array}{l}\text { Total } n \\
(\%)\end{array}$ \\
\hline \multicolumn{5}{|l|}{ Hemoglobin } \\
\hline Normal & $40(83.3)$ & $46(100)$ & \multirow[t]{2}{*}{$0.004^{*}$} & $86(91.5)$ \\
\hline Not normal & $8(16.7)$ & 0 & & $8(8.5)$ \\
\hline \multicolumn{5}{|l|}{ TLC } \\
\hline Normal & $26(54.2)$ & $38(82.6)$ & \multirow[t]{2}{*}{$0.003^{*}$} & $64(68.1)$ \\
\hline Not normal & $22(45.8)$ & $8(17.4)$ & & 30 (31.9) \\
\hline \multicolumn{5}{|l|}{ Neutrophil count } \\
\hline Normal & $1(2.1)$ & $7(15.2)$ & \multirow[t]{2}{*}{$0.023^{*}$} & $8(8.5)$ \\
\hline Not normal & $47(97.9)$ & $39(84.8)$ & & $86(91.5)$ \\
\hline \multicolumn{5}{|l|}{ Lymphocyte count } \\
\hline Normal & $4(8.3)$ & $43(93.5)$ & \multirow{2}{*}{$0.001^{*}$} & $47(50)$ \\
\hline Not normal & $44(91.7)$ & $3(6.5)$ & & $47(50)$ \\
\hline \multicolumn{5}{|l|}{ Monocyte count } \\
\hline Normal & $2(4.2)$ & 41 (89.1) & \multirow[t]{2}{*}{$0.001^{*}$} & $43(45.7)$ \\
\hline Not normal & $46(95.8)$ & $5(10.9)$ & & $51(54.3)$ \\
\hline \multicolumn{5}{|l|}{ Platelet count } \\
\hline Normal & $42(87.5)$ & $42(91.3)$ & \multirow[t]{2}{*}{0.55} & $84(89.4)$ \\
\hline Not normal & $6(12.5)$ & $4(8.7)$ & & $10(10.6)$ \\
\hline \multicolumn{5}{|l|}{ Bilirubin } \\
\hline Normal & $44(91.7)$ & $46(100)$ & \multirow[t]{2}{*}{$0.045^{\star}$} & $90(95.7)$ \\
\hline Not normal & $4(8.3)$ & 0 & & $4(4.3)$ \\
\hline \multicolumn{5}{|l|}{ AST } \\
\hline Normal & $28(58.3)$ & $41(89.1)$ & \multirow[t]{2}{*}{$0.001^{*}$} & $69(73.4)$ \\
\hline Not normal & $20(41.7)$ & $5(10.9)$ & & $25(26.6)$ \\
\hline \multicolumn{5}{|l|}{ ALT } \\
\hline Normal & $24(50)$ & $44(95.7)$ & \multirow[t]{2}{*}{$0.001^{*}$} & $68(72.3)$ \\
\hline Not normal & $24(50)$ & $2(4.3)$ & & $26(27.7)$ \\
\hline \multicolumn{5}{|l|}{ Urea } \\
\hline Normal & $3(6.2)$ & $18(39.1)$ & \multirow[t]{2}{*}{$0.001^{*}$} & $21(22.3)$ \\
\hline Not normal & $45(93.8)$ & $28(60.9)$ & & $73(77.7)$ \\
\hline \multicolumn{5}{|l|}{ Creatinine } \\
\hline Normal & $37(77.1)$ & $38(82.6)$ & \multirow[t]{3}{*}{0.505} & $75(79.8)$ \\
\hline Not normal & $11(22.9)$ & $8(17.4)$ & & $19(20.2)$ \\
\hline Total & 48 (51.1) & $46(48.9)$ & & $94(100)$ \\
\hline
\end{tabular}

Table 5 shows a comparative assessment of clinical presentations among COVID-19 and nonCOVID-19 pregnant women.

Table 5: Comparative assessment of clinical presentations among COVID-19 and non-COVID-19 pregnant women

\begin{tabular}{lllll}
\hline Clinical presentation & $\begin{array}{l}\text { COVID-19 } \\
\text { positive } \mathrm{n}(\%)\end{array}$ & $\begin{array}{l}\text { COVID-19 } \\
\text { negative } \mathrm{n}(\%)\end{array}$ & p-value & $\begin{array}{l}\text { Total } \mathrm{n} \\
(\%)\end{array}$ \\
\hline Flu & $26(54.2)$ & $1(2.2)$ & $0.001^{*}$ & $27(28.7)$ \\
Cough & $27(56.2)$ & $1(2.2)$ & $0.001^{*}$ & $28(29.8)$ \\
Fever & $27(56.2)$ & $1(2.2)$ & $0.001^{*}$ & $28(29.8)$ \\
Aches and pains & $24(50)$ & $1(2.2)$ & $0.001^{*}$ & $25(26.6)$ \\
Sore throat & $19(39.6)$ & $1(2.2)$ & $0.001^{*}$ & $20(21.3)$ \\
Shortness of breath & $12(25)$ & 0 & $0.001^{*}$ & $12(12.8)$ \\
Red eyes & $2(4.2)$ & 0 & 0.162 & $2(2.1)$ \\
Loose motion & $1(2.1)$ & 0 & 0.325 & $1(1.1)$ \\
Cyanosis & $3(6.2)$ & 0 & 0.085 & $3(3.2)$ \\
No symptoms & $21(43.8)$ & $45(97.8)$ & $0.001^{*}$ & $66(70.2)$ \\
\hline The test applied: Chi-square test, $\left(^{*}\right)$ : Indicates statistically significant difference, COVID-19: Coronavirus
\end{tabular}
disease 2019.

Flu, cough, fever, aches and pains, sore throat, and shortness of breath occurred with significantly high prevalence among COVID-19 positive subjects than among COVID-19 negative subjects.

Table 6 shows Chest $\mathrm{X}$-ray before and after delivery among COVID-19 positive subjects.

Table 6: Comparative assessment of imaging parameters before and after delivery among COVID-19 women

\begin{tabular}{llll}
\hline Chest X-ray & Before delivery n (\%) & After delivery $\mathrm{n}(\%)$ & $\mathrm{p}$-value \\
\hline Not done & $39(83)$ & $42(89.4)$ & 0.083 \\
Mild changes & $6(12.8)$ & $3(6.4)$ & \\
Severe infiltrates & $2(4.3)$ & $2(4.3)$ & \\
\hline COVID-19: Coronavirus disease 2019. & &
\end{tabular}


Only two subjects had severe infiltrates before as well as after delivery. The proportion of those with mild changes before delivery $(12.8 \%)$ reduced after delivery $(6.4 \%)$, but the difference was statistically significant $(p=0.083)$.

\section{Discussion}

The study revealed that pregnant women diagnosed as COVID-19 positive were housewives under 30 years of age. The most common symptoms included flu, cough, fever, aches and pains, sore throat, and shortness of breath. Chest X-ray demonstrated mild and severe infiltrates in $6(12.8 \%)$ and $2(4.3 \%)$ pregnant women before delivery. The majority of the neonates was delivered through cesarean section and was above $2.5 \mathrm{~kg}$ weight with an Apgar score above 10. Only $3(12 \%)$ neonates born to COVID-19 positive mothers were admitted to NICU. The blood parameters revealed that a significantly more proportion of COVID-19 positive pregnant women had abnormal hemoglobin, TLC, neutrophil count, lymphocyte count, monocyte count, bilirubin, aspartate aminotransferase, alanine aminotransferase, and urea levels.

A systematic review by Panahi et al. on 37 pregnant mothers with COVID-19 reported that the age range of mothers was between 23 and 40 years. Babies were delivered through the cesarean section in 29 women, and eight women had a normal delivery. Preterm labor was reported in seven women at 30-33 weeks of gestational age, and the remaining women had a delivery in the third trimester (between 34 and 40 weeks gestation) [10]. Similarly, a case series report by Perrone et al. evaluated four convalescent mothers with COVID-19 and found that all three babies were above $2.5 \mathrm{~kg}$ with an APGAR score above 9 [11]. Another study reported $4.1 \%$ preterm delivery and $2.2 \%$ miscarriage [12].

In the present study, the majority of the COVID-19 positive mothers had flu, cough, fever, aches and pains, sore throat, and shortness of breath. The present study was in line with the Yang et al. study conducted at a non-designated hospital of Wuhan on 13 pregnant women with Corona infection. Most of the women were asymptomatic and had milder symptoms of prenatal fever (15.4\%), postpartum fever $(61.6 \%)$, and coughing cases (15.4\%) [13]. Similarly, a systematic review reported by Ashraf et al. revealed that the most common symptoms among pregnant women included cough $(n=34)$, fever $(n=47)$, and dyspnea. The temperatures were between $37^{\circ} \mathrm{C}$ and $38.8^{\circ} \mathrm{C}$ [14]. In a systematic review by Zaigham and Andersson on 108 pregnancies in the COVID-19 pandemic, they reported that most of the pregnant women had a fever, cough, and Iymphocytopenia with elevated C-reactive protein, and most of them delivered through cesarean section [15]. Another study reported that the high-risk pregnancy group had a significantly higher RT-PCR positivity rate compared with the low-risk pregnancy group $(2.9 \%$ vs. $0 \%, p=0.04)$ [16].

When comparing hematological parameters, significant abnormal differences were observed in hemoglobin, TLC, neutrophil count, lymphocyte count, monocyte count, bilirubin, AST, ALT, and urea levels among the COVID-19 positive group compared with the negative group. In Yang et al. study, there were no differences in leukocyte count, neutrophil granulocytes, lymphocyte counts, and CRP between Corona confirmed group and control group before and after delivery [13]. The present study results are consistent with Chen et al. findings and might be related to persistent infection and prolonged hypoxia resulting in bone marrow hyperplasia to deliver more granulocytes [17]. The abnormal lymphocyte count may be caused by the severe acute respiratory syndrome coronavirus 2 (SARS-CoV-2) continuous invasion and proliferation, causing the death or depletion of lymphocytes when they reach the spleen and other immune organs [18].

The X-ray findings in the current study found mild changes (12.8\%) and severe infiltrates 2 (4.3) before delivery. A systematic review by Turan et al. in 221 Chinese women with mild COVID-19 reported that they had abnormal X-ray and chest CT and findings (88.7\%). Abnormal pulmonary findings among pregnant women included focal unilateral or bilateral groundglass opacities, diffuse, bilateral ground-glass opacities with subpleural involvement, and pleural effusion. These X-ray findings help in evaluating the extent and severity of the disease and in the early screening of highly suspected patients [19].

In the present study, none of the neonates were COVID-19 positive. Whereas, in a study conducted by Zeng et al. in China, 33 women with COVID-19 infection delivered through cesarean section. Out of 33 newborns, only three acquired COVID-19, a postnatal transmission was postulated since PCR assays revealed that breast milk, cord blood, and amniotic fluid were all clear from the virus [20].

Women experience physiological and immunological changes during pregnancy, making them more prone to viral respiratory infections, such as influenza. High fevers in early pregnancy are connected with specific birth defects, such as neural tube defects [21]. Published studies to date seem to be reassuring that pregnant women with COVID-19 might not be at increased risk for severe complications or adverse reproductive health outcomes [10], [11], [13]. CDC stated that pregnant women should meticulously follow the safety measures that were recommended for health-care providers [22]. In addition, maintaining appropriate self-care and hygiene practice during pregnancy is crucial to reduce the morbidity and complications of the COVID-19 infection [23]. 
The available guidelines for the management of pregnant women with COVID are rapidly changing and getting updated with time. Due to the limited number of cases analyzed and the short duration of the study period, multiple strategies are required, including sentinel surveillance and seroprevalence studies to address the knowledge gaps on the effects of COVID-19 during pregnancy.

There are a few limitations to the study. First, the sample size was limited, and all of the pregnant women confirmed with COVID-19 were not classified based on mild, moderate, and severe symptoms. Second, the antibody titers and viral load kinetics were not determined in the study. Further large-scale, multicentric studies with larger sample sizes are expected to determine the management protocols at the time of delivery to inhibit the transmission and complications of infection in the mothers and neonates.

\section{Conclusions}

Pregnant women and their infants are the most vulnerable cases in this COVID-19 outbreak because of their susceptibility to infections, altered physiology, and compromised immunological functions. The present study provided crucial insights into epidemiological and clinical features during the perinatal period. Chest $\mathrm{X}$-rays and blood routine examination are reliable findings to prevent COVID-19 complications among pregnant women. None of the neonates were found to be COVID-19 positive, which mandates to explore reliable evidence on mechanisms of vertical transmission. Health-care professionals also need to formulate obstetric management principles to safeguard the fetus and pregnant women affected with COVID-19 infection.

\section{Author contribution}

Saadia, Z. and Farrukh, R. designed the experiment, analyzed the data, and wrote the manuscript; S.Z. analyzed the data; Kanwal. S. and Sumaira, Q. collected the data and helped in discussion writing.

\section{References}

1. World Health Organization. Coronavirus Disease 2019 (COVID-19): Situation Report. Geneva: World Health Organization; 2020. p. 60.
2. Schwartz DA. An analysis of 38 pregnant women with COVID-19, their newborn infants, and maternal-fetal transmission of SARS-CoV-2: Maternal coronavirus infections and pregnancy outcomes. Arch Pathol Lab Med. 2020;144(7):799-805. https:// doi.org/10.5858/arpa.2020-0901-sa

\section{PMid:32180426}

3. Arbabzadeh T, Noori N, Najafian A, Ghasemi M. Assessment of corona in pregnant women: Epidemiology, clinical signs, prevention and treatment. J Complement Med Res. 2020;11(3):118-30. https://doi.org/10.5455/jcmr.2020.11.03.15

4. Ellington S, Strid P, Tong VT, Woodworth K, Galang RR, Zambrano LD, et al. Characteristics of women of reproductive age with laboratory-confirmed SARS-CoV-2 infection by pregnancy status-United States, January 22-June 7, 2020. MMWR Morb Mortal Wkly Rep. 2020;69(25):769. https://doi. org/10.15585/mmwr.mm6925a1

PMid:32584795

5. Badr DA, Mattern J, Carlin A, Cordier AG, Maillart E, E Hachem L, et al. Are clinical outcomes worse for pregnant women at $\geq 20$ weeks' gestation infected with coronavirus disease 2019? A multicenter case-control study with propensity score matching. Am J Obstet Gynecol. 2020;223(5):764-8. https://doi.org/10.1016/j.ajog.2020.07.045 PMid:32730899

6. Yu N, Li W, Kang Q, Xiong Z, Wang S, Lin X, et al. Clinical features and obstetric and neonatal outcomes of pregnant patients with COVID-19 in Wuhan, China: A retrospective, singlecentre, descriptive study. Lancet Infect Dis. 2020;20(5):559-64. https://doi.org/10.1016/s1473-3099(20)30176-6

7. Anand P, Yadav A, Debata P, Bachani S, Gupta N, Gera R. Clinical profile, viral load, management and outcome of neonates born to COVID 19 positive mothers: A tertiary care centre experience from India. Eur J Pediatr. 2020;180(2):54759. https://doi.org/10.1007/s00431-020-03800-7 PMid:32910210

8. Centers for Disease Control and Prevention. Centers for Disease Control and Prevention Coronavirus Disease 2019 (COVID-19) 2020. United States: Centers for Disease Control and Prevention; 2020.

9. Government of Pakistan. Sexual Reproductive and Maternal Health Services during COVID-19. 2020. Available from: https:// www.covid.gov.pk/guideline.

10. Panahi L, Amiri M, Pouy S. Risks of novel coronavirus disease (COVID-19) in pregnancy; a narrative review. Arch Acad Emerg Med. 2020;8(1):e34.

PMid:32232217

11. Perrone S, Deolmi M, Giordano M, D'Alvano T, Gambini L, Corradi $\mathrm{M}$, et al. Report of a series of healthy term newborns from convalescent mothers with COVID-19. Acta Biomed. 2020;91(2):251.

PMid:32420961

12. Sahin D, Tanacan A, Erol SA, Anuk AT, Yetiskin FD, Keskin HL, et al. Updated experience of a tertiary pandemic center on 533 pregnant women with COVID-19 infection: A prospective cohort study from Turkey. Int J Gynaecol Obstet. 2021;152(3):328-34. https://doi.org/10.1002/ijgo.13460

13. Yang $\mathrm{H}$, Sun $\mathrm{G}$, Tang $\mathrm{F}$, Peng M, Gao Y, Peng J, et al. Clinical features and outcomes of pregnant women suspected of coronavirus disease 2019. J Infect. 2020;81(1):e40-4. https:// doi.org/10.1016/j.jinf.2020.04.003

14. Ashraf MA, Keshavarz $P$, Hosseinpour $P$, Erfani A, Roshanshad $A$, Pourdast A, et al. Coronavirus disease 2019 (COVID-19): A systematic review of pregnancy and the possibility of vertical transmission. J Reprod Infertil. 2020;21(3):157-68.

PMid:32685412

15. Zaigham $\mathrm{M}$, Andersson $\mathrm{O}$. Maternal and perinatal outcomes 
with COVID-19: A systematic review of 108 pregnancies. Acta Obstet Gynecol Scand. 2020;99(7):823-9. https://doi. org/10.1111/aogs.13867

PMid:32259279

16. Tanacan A, Erol SA, Turgay B, Anuk AT, Secen EI, Yegin GF, et al. The rate of SARS-CoV-2 positivity in asymptomatic pregnant women admitted to hospital for delivery: Experience of a pandemic center in Turkey. Eur J Obstet Gynecol Reprod Biol. 2020;253:31-4. https://doi.org/10.1016/j.ejogrb.2020.07.051

PMid:32763728

17. Chen G, Wu D, Guo W, Cao Y, Huang D, Wang H, et al. Clinical and immunologic features in severe and moderate forms of coronavirus disease. J Clin Invest. 2019;130(5):2620-9.

PMid:32217835

18. Wang C, Deng R, Gou L, Fu Z, Zhang X, Shao F, et al. Preliminary study to identify severe from moderate cases of COVID-19 using combined hematology parameters. Ann Transl Med. 2020;8(9):593. https://doi.org/10.21037/atm-20-3391 PMid:32566620

19. Turan O, Hakim A, Dashraath $P$, Jeslyn WJ, Wright $A$, Abdul-Kadir R. Clinical characteristics, prognostic factors, and maternal and neonatal outcomes of SARS-CoV-2 infection among hospitalized pregnant women: A systematic review. Int J Gynecol Obstet. 2020;151(1):7-16. https://doi.org/10.1002/ ijgo.13329

PMid:32816307

20. Zeng L, Xia S, Yuan W, Yan K, Xiao F, Shao J. Neonatal earlyonset infection with SARS-CoV-2 in 33 neonates born to mothers with COVID-19 in Wuhan, China. JAMA Ped. 2020;174(7):7225. https://doi.org/10.1001/jamapediatrics.2020.0878 PMid:32215598

21. Rasmussen SA, Smulian JC, Lednicky JA, Wen TS, Jamieson DJ. Coronavirus disease 2019 (COVID-19) and pregnancy: What obstetricians need to know. Am J Obstetr Gynecol. 2020;222(5):415-26. https://doi.org/10.1016/j. ajog.2020.02.017 PMid:32105680

22. Rasmussen SA, Kissin DM, Yeung LF, MacFarlane K, Chu SY, Turcios-Ruiz RM, et al. Preparing for influenza after 2009 H1N1: Special considerations for pregnant women and newborns. Am J Obstet Gynecol. 2011;204(6):S13-20. https://doi.org/10.1016/j. ajog.2011.01.048 PMid:21333967

23. Mirzadeh M, Khedmat L. Pregnant women in the exposure to COVID-19 infection outbreak: The unseen risk factors and preventive healthcare patterns. J Matern Fetal Neonatal Med. 2009:1-2. https://doi.org/10.1080/14767058.2020.1749257

PMid:32223477 